\title{
Static Strength and Modal Analysis of Crankshaft of a High-speed Reciprocating Compressor
}

\author{
Guangyu $\mathrm{Mu}^{1,2, \mathrm{a}}$, Feng Wang ${ }^{3, \mathrm{~b}}$ and Xiaozhen $\mathrm{Mi}^{3, \mathrm{c}}$ \\ ${ }^{1}$ Department of Mechanical and Power Engineering, Dalian Ocean University, China \\ ${ }^{2}$ Mechanical Engineering College, Dalian JiaoTong University, China \\ ${ }^{3}$ Institute of Modern Rail Transportation, Dalian JiaoTong University, China

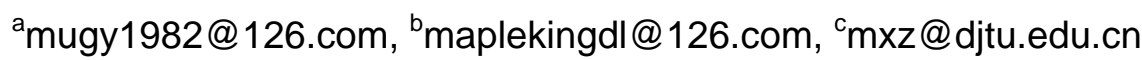

Keywords: Reciprocating Compressors; Crankshaft; Static Strength Analysis; Torsional Vibration; Modal Analysis

\begin{abstract}
Crankshaft is the main part of reciprocating compressor. Its structure parameters influence the reliability and service life. In order to improve the reliability of the crankshaft, Finite Element Method (FEM) is applied for three-dimensional modeling and static strength analysis. The shaft model is established and imported into ANSYS, then imposed the appropriate constrains, and applied load. The stress of crankshaft journal under the maximum comprehensive piston force was obtained accordingly. In addition the main destruction form of crankshaft is torsion vibration. For this purpose, 6 model of the crankshaft was analyzed for reduce the deformation and torsional vibration based on Modal Analysis. They can provide a theoretical basis for the further design optimization of the crankshaft.
\end{abstract}

\section{Introduction}

Crankshaft is one of the key components of piston compressor, which carries alternating load such as gas power, friction, reciprocally rotating inertia force and input torque during the operation[1]. According to experience, crankshaft breakages mainly appears at the transition arc among main shaft, crank pin and crank junction, we should try to reduce stress concentration at the journal fillet for improving the fatigue strength of crankshaft. The alternating load could cause bending, torsional vibration, bending and torsion mixing and fatigue failure of the crankshaft, which would strengthen the wear of connecting rod, bearing, valves and other parts within a certain operation speed range. It needs to be given more attention that crankshaft bending and torsional vibrations may cause abnormal complexes between connecting rod and bearing, bearing and crank, rod small head and bush, the bush and the cross pin, which leads to bush-burning or shaft - broken, initiates the piston scraping the cylinder wall or partial grinding failure. Therefore, the study of force deformation and natural frequency has important guiding significance for improving and optimizing the structure of the crankshaft.

\section{Finite element analysis of crankshaft}

A crankshaft commonly used in small and medium sized refrigeration compressor is adopt for the study. The main dimensions are as follows:

main shaft diameter $\mathrm{D}_{1}=44.4 \mathrm{~mm}$, crank pin diameter $\mathrm{D}=44.4 \mathrm{~mm}$, crank pin length $\mathrm{L}=71.2 \mathrm{~mm}$; intermediate crank thickness $S=26.2 \mathrm{~mm}$, both sides of the crank thickness $\mathrm{S}=24 \mathrm{~mm}$;

crank width $B=65 \mathrm{~mm}$, total length of crank crankshaft $=545.6 \mathrm{~mm}$;

crankshaft material is $40 \mathrm{Cr}$, reciprocating mass is $0.4756 \mathrm{~kg}$;

compressor rated speed is $1450 \mathrm{r} / \mathrm{min}$, rated power is $2.09 \mathrm{~kW}$;

physical characteristics: density $\rho=7.82 \times 10-6 \mathrm{~kg} / \mathrm{mm}^{3}$, the elastic modulus $\mathrm{E}=198 \mathrm{Gpa}$, Poisson's ratio $\mu=0.3$. 
Model and load determined. Pro/Engineer software is used to build three-dimensional model of the compressor crankshaft. Taking into account oil channel holes junction with the journal would appear bad unit in meshing process, the oil paths were omitted in the model[2].

The main loads exerting on the crankshaft includes connecting rod force and rotating inertia force. The segmentation method is applied to simplify force of the crankshaft as follows[3].

1) For multi-support crankshaft, as a consideration of simply supported beam cuting at the midpoint of main bearing to components segment.

2) stress of connecting rod concentrately exerted at the intermediate position of crankpin.

3) omitted rotary inertia force.

4) omitted crankshaft weight.

Meshing and constraints identified. The crankshaft model is meshed with tetrahedral units (solid95). The grid at the fillet of connecting rod journal and crank arm, main journal and crank arm was refinement processing. The meshed model has 219,095 nodes and 612,220 units. The finite element mesh model of crankshaft is shown in Figure 1.

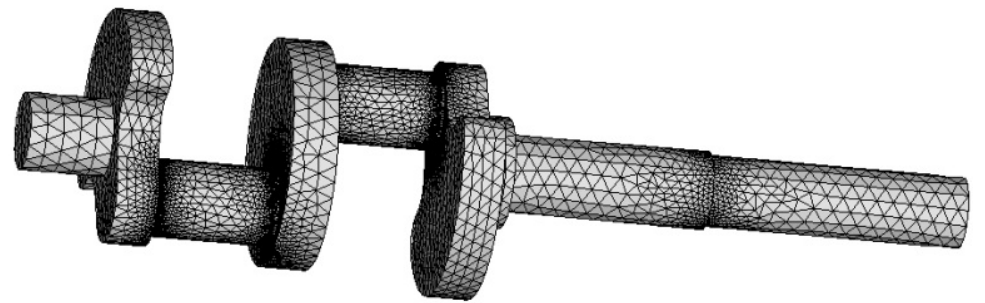

Figure 1 Finite element mesh model of crankshaft

The main constraint is used to eliminate the displacement of the crankshaft model, which enabled the crankshaft to rotate only around $\mathrm{X}$ axis, to limit the freedom of movement[4]. Specific performance:

1) The constraints imposed on the left end surface of the main shaft could limit the movement freedom of the end face nodes;

2) Since the right end of main shaft is supported by bearings, the nodes at the position of bearings should be loaded constraints for restricting the $\mathrm{Y}$-axis and Z-axis direction of movement freedom.

Exerting load. The connecting rod force which crank pin suffered was broken down into normal force and tangential force, and divided into 36 parts. Torque of power input is simplified to the tangential force exerting on the circumference face by $\mathrm{F} \times \mathrm{d}$ mode, where $\mathrm{F}=8831 \mathrm{~N}$, main shaft diameter $d=0.0404 \mathrm{~m}$. At the same time, the power input section of crankshaft needs to make steel processing for reducing the stress concentration caused by the force focused on a node. The force value of crank pin loading is shown in Table 1, the crankshaft model of applied load is shown in Figure2.

Table 1. Loads on crankshaft

\begin{tabular}{|c|c|c|c|c|c|c|}
\hline \multirow[b]{2}{*}{$\begin{array}{c}\text { Crankshaft position } \\
\text { feature }\end{array}$} & \multicolumn{2}{|c|}{ The first crankpin } & \multicolumn{2}{|c|}{ The second crankpin } & \multirow[b]{2}{*}{$\begin{array}{c}\text { Input } \\
\text { torque } \\
T \text { (Nm) }\end{array}$} & \multirow{2}{*}{$\begin{array}{l}\text { Input } \\
\text { Forc } \\
\text { e } \\
F(\mathrm{~N}) \\
\end{array}$} \\
\hline & $\begin{array}{c}\text { Normal force } \\
F_{r}^{\prime}(\mathbf{N})\end{array}$ & $\begin{array}{c}\text { Tangential } \\
\text { force } \\
\mathbf{F}_{t}^{\prime}(\mathbf{N})\end{array}$ & $\begin{array}{l}\text { Normal force } \\
\qquad F_{\mathbf{r}}(\mathbf{N})\end{array}$ & $\begin{array}{c}\text { Tangential } \\
\text { force } \\
F_{t}(\mathbf{N})\end{array}$ & & \\
\hline $\begin{array}{l}\text { The largest comprehensive } \\
\text { piston force }\end{array}$ & -595.05 & 9949 & -7325 & 244.2 & 356.78 & 8831 \\
\hline $\begin{array}{l}\text { A Cylindrical Support: } 0 . \mathrm{mm} \\
\text { B Cylindrical Support 2: } 0 . \mathrm{mm} \\
\text { C Moment. } 3.5678 \mathrm{e}+005 \mathrm{~N} \cdot \mathrm{mm} \\
\text { D Force: } 7325.1 \mathrm{~N} \\
\text { E Force } 2: 244.18 \mathrm{~N} \\
\text { F Force } 3: 595.05 \mathrm{~N} \\
\text { G Force } 4: 244.18 \mathrm{~N}\end{array}$ & & & & & & \\
\hline
\end{tabular}

Figure 2 Stress distribution of the crankshaft

Figure 3 Crankshaft model of applied load 
Result analysis. Static strength analysis of the crankshaft is carried out at the operating condition of the maximum pistons comprehensive force. It was found that the maximum stress was 82Mpa at the left of second crank connected to the crank pin and crank fillet, viewing from motor where located in the vicinity of 300 degrees counter-clockwise. According to experience, the destruction of crankshaft also mainly occurs at fillet, which happens to coincide with the calculated results. It was indicated that the finite element analysis model is valid. Stress distribution of the crankshaft is shown in Figure3.

\section{Modal Analysis of Crankshaft}

It is essential to research vibration characteristics of crankshaft in design and manufacture of compressors[5].The occurrence reasons of torsional vibration destruction of the high-speed operation crankshaft canbe revealled by modal analysis. The first 6 model of the crankshaft was analyzed for avoid resonance at runtime. Due to the vibration mode and natural frequency was only related to stiffness and mass of the crankshaft, chamfer and oil holes in the finite element model of the crankshaft were ignored. Modal analysis is a typical characteristic value problems. Multi-stage vibration natural frequencies and the corresponding mode vectors could be obtained by solving the eigenvalue equation. The compressor crankshaft vibration differential equation is as follows:

$$
[M]\{\ddot{X}\}+[K]\{X\}+[B]\{\dot{X}\}=\{F\}
$$

Where $[\mathrm{M}]$--- quality matrix; [K]--- stiffness matrix; [B]--- damping matrix;

$\{F\}$--- crank overall nodal loads column vector; $\{X\}$--- displacement vector;

$\{\dot{X}\}$--- velocity vector; $\{\ddot{X}\}$--- acceleration vector;

In order to obtain the natural frequency, damping system $[\mathrm{B}]$ and forces $\{\mathrm{F}\}$ are ignored. The equation was changed as follows:

$$
[M]\{\ddot{X}\}+[K]\{X\}=0
$$

If the structure vibrated with a natural frequency, that is $\{X\}=\{\phi\} \sin (\omega t+\varphi)$, substituted into the formula (2):

$$
\left([K]-\omega^{2}[M]\{\varphi\}=\{0\}\right.
$$

$\{\varphi\}=\{0\}$ is one solution, which means all nodes in the structure are in a quiescent state. Therefore, for the sake of nonzero solution, it must be met $\operatorname{det}\left([K]-\omega^{2}[M]\right)=\{0\}$, which is the vibration characteristic equation. And the square root of eigenvalues $\omega_{i}$ is the natural frequency of freedom vibration of the structure. The feature vector $\left\{\varphi_{i}\right\}$ is the corresponding modal vector of $\omega_{i}[6]$. However, the analytic solution of above differential equation can not be obtained, which can be solved by the finite element method.

In this paper, the modal analysis was calculated by means of Block Lanczos method provided by ANSYS. The 6 modal shapes were shown in Figure 4.

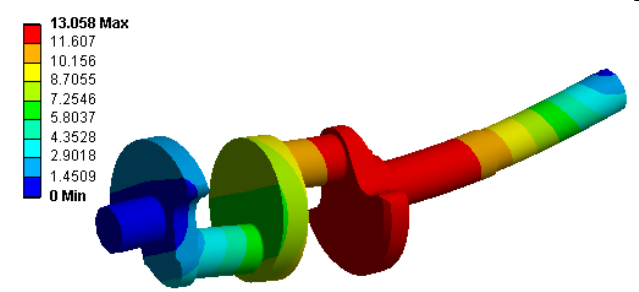

(a)The 1st modal shape

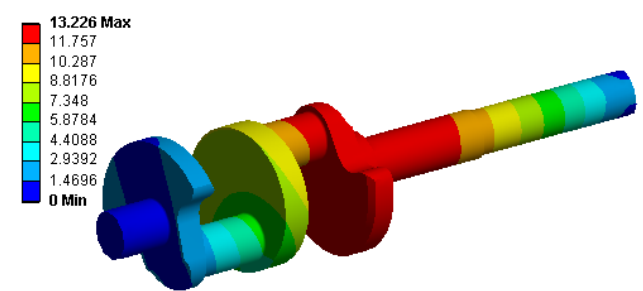

(b) The 2nd modal shape 


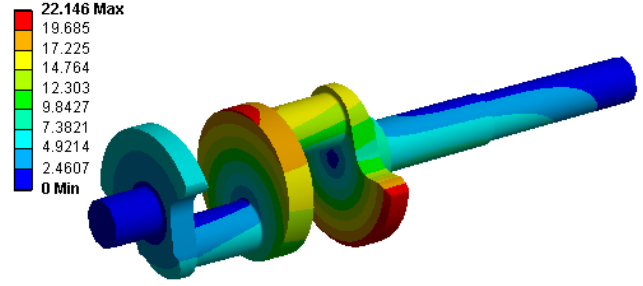

(c)The 3rd modal shape

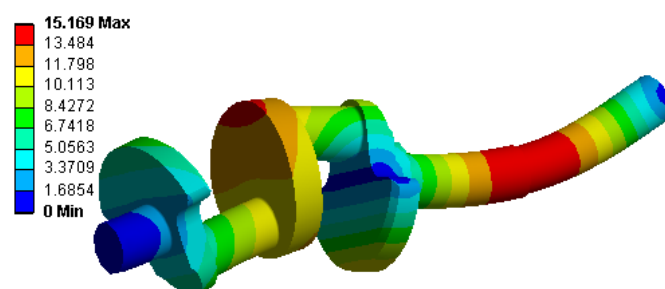

(e)The 5th modal shape

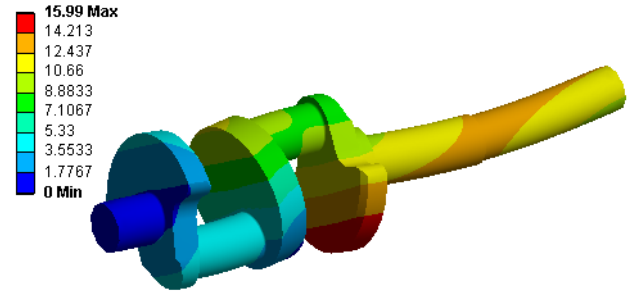

(d) The 4th modal shape

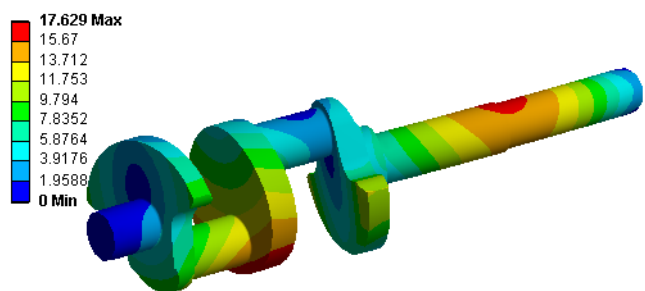

(f) The 6th modal shape

Figure 4. The modal shape of high-speed reciprocating compressor crankshaft

Among the results, the first to fourth modal shape were bending vibration mode, and the fifth and sixth modal shape were torsional vibration mode. The natural frequency of 6 vibration modal shape are shown in Table 2

Table 2 The natural frequency of 6 vibration modal shape of compressor crankshaft

\begin{tabular}{|c|c|c|c|c|c|c|}
\hline Set & 1 & 2 & 3 & 4 & 5 & 6 \\
\hline Frequency/Hz & 32.62 & 43.28 & 121.94 & 264.31 & 448.66 & 692.23 \\
\hline Modal shape & $\begin{array}{c}\text { Bend } \\
\text { modal } \\
\text { shape }\end{array}$ & $\begin{array}{c}\text { Bend } \\
\text { modal } \\
\text { shape }\end{array}$ & $\begin{array}{c}\text { Bend } \\
\text { modal } \\
\text { shape }\end{array}$ & $\begin{array}{c}\text { Bend } \\
\text { modal } \\
\text { shape }\end{array}$ & $\begin{array}{c}\text { Torsional } \\
\text { model } \\
\text { shape }\end{array}$ & $\begin{array}{c}\text { Torsional } \\
\text { model } \\
\text { shape }\end{array}$ \\
\hline
\end{tabular}

While the rotation speed is $1450 \mathrm{r} / \mathrm{min}$, the operating frequency of the crankshaft is $24 \mathrm{~Hz}$ correspondingly. As can be seen from the results in table 2, the operating frequency was less than the minimum natural frequency of the crankshaft $\omega_{1}=32.62 \mathrm{~Hz}$, so that the crankshaft resonance damage does not occur when the compressor operating at 1450 $\mathrm{r} / \mathrm{min}$. Crankshaft torsional deformation and vibration can be reduced by taking measures of rolling process or increase the fillet radius.

\section{Conclusion}

In order to increase the strength of the crankshaft, the static stress analysis has been carried out . It was found that the maximum stress was $82 \mathrm{Mpa}$ at the left of second crank connected to the crank pin and crank fillet. The maximum stress can be reduced gradually with the common radius $\mathrm{R}$ increases appropriately. The natural frequency and modal shapes of crankshaft can be easily and accurately obtained with the method of modal analysis. It was found that the excitation frequency of high-speed crankshaft is less than its natural frequency, resonance phenomenon can not occur. If the crankshaft excitation frequency coincides with the natural frequency, the tuner could be used to improve the natural frequency of the crankshaft effectively and avoid resonance phenomenon. The resluts would play an important role in high-speed reciprocating piston compressor crankshaft improvement and parameters optimization.

\section{Acknowledgements}

This work was financially supported by the Liaoning Provincial Department of Education (L2013280).

\section{Reference}

[1] Yu Yongzhang, Sun Tanying, Chen Hongjun. Displacement Compressors Technical Manual: chemical, power, cooling [M] . Machinery Industry Press, 2000. 
[2] He Xiaoming, ZengRubu. Pro/E Behavioral Modeling Technology Applied in Mechanical Design [J] .mechanical design and manufacturing, 2005(5):52-53.

[3] Yang, Z. Application of the Finite Piece Method to Simulate Viscoelastic Fluid Flows in L-shaped Channel. Applied Mechanics and Materials, vol. 538 (2014), p100-103.

[4] Yu BY, Feng QK, Yu XL. Dynamic Simulation and Stress Analysis for Reciprocating Compressor Crankshaft[J]. Proceedings of the Institution of Mechanical Engineers, Part C: Journal of Mechanical Engineering Science, 2013, 227(4):845-851.

[5] R. Dufour, J. Der Hagopian and M. Lalanne, Transient and steady state dynamic behavior of single cylinder compressors: prediction and experiments, Journal of Sound and Vibration (1995)181(1), 23-41.

[6] Zissimos P. i. A crankshaft system model for structural dynamic analysis of internal combustion engines, Computer\&Structures 79(2001), 2009-2027. 